Article

\title{
Evaluation of Net Energy Obtainable from Combustion of Stabilised Olive Mill By-Products
}

\author{
Antonio Messineo ${ }^{1, *}$, Roberto Volpe ${ }^{1}$ and Francesco Asdrubali ${ }^{2}$ \\ 1 Faculty of Engineering and Architecture, University of Enna Kore, Cittadella Universitaria, \\ Enna 94100, Italy; E-Mail: roberto.volpe@unikore.it \\ 2 Department of Industrial Engineering, University of Perugia, Via G. Duranti 67, Perugia 06125, \\ Italy; E-Mail: fasdruba@unipg.it \\ * Author to whom correspondence should be addressed; E-Mail: antonio.messineo@unikore.it; \\ Tel.: +39-0935-536448; Fax: +39-0935-536951.
}

Received: 22 March 2012; in revised form: 23 April 2012 / Accepted: 10 May 2012 /

Published: 11 May 2012

\begin{abstract}
This work is aimed at calculating the energy content of the residues from olive oil production. Olive pulp, olive husk and sludge (a mixture of olive pulp and husk) have been analyzed separately. Olive Mill Effluents (OME) are normally a problem for olive mill farms, yet they may be used as feedstock for biomass-fuelled power plants. Nonetheless, OMEs are characterized by a relatively high humidity content and are produced only during the olive season. Thus, OME need a stabilization process to be employed as a solid biofuel throughout the year. The analyses conducted attempt an evaluation of the energy consumption of a three-stage stabilization process: drying, milling and pelletising. The net electrical energy available from OME is then calculated as a difference between gross energy available and energy consumed for stabilization. The gross available electrical energy was calculated based on direct energy conversion of the stabilized feedstock on a small scale direct combustion and Organic Rankine Cycle (ORC) turbine. Results show that $\mathrm{OME}$ are suitable for energy production. Approximately $4500 \mathrm{~kJ} / \mathrm{kg}$ of net electrical energy may be obtained out of olive sludge or olive pulp, while olive husk shows a potential gross energy of $3400 \mathrm{~kJ} / \mathrm{kg}$.
\end{abstract}

Keywords: olive mill effluents; energy conversion; stabilization process; drying; milling; pelletising 


\section{Introduction}

While energy has become a central topic on the European and Italian political agenda, bioenergies have attracted the attention of researchers, operators and policy makers [1,2]. In particular, in Italy, energy production from biomass is significantly subsidized through incentive schemes designed to economically sustain investments.

Although it is well accepted that agriculture can contribute to increase the rate of renewable energy production, and thus reduce fossil fuel dependency and green house gas (GHG) emissions [3-5], it is not equally well known that an important part of this energy can be obtained from agro-wastes and in particular from ligno-cellulosic agro-wastes, such as OME.

Statistical data show an increase of areas destined to energy crops such as those dedicated to extraction of pure vegetable oil (sunflower, soy, etc.), potentially interesting for bio-energy production. This trend is heavily criticized for its potential contribution to reduction of the area destined to food crops [6,7]. For this reason, this study evaluates the possibility to produce energy from agricultural by-products such as OME. Amidst different technologies for energy production, small size cogeneration plants are among the most promising alternatives to produce power and heat from such residues.

This consideration is directly linked to the high humidity content and relatively low energy density of the feedstock; transportation costs are particularly significant with regards to the net energy available from feedstock. Hence, small scale plants prove more convenient, especially in areas where biomass is dispersed and the orographic conformation of land does not allow for mechanization of the biomass collection [8].

The agro-food sector is particularly important especially for some agricultural areas of Sicily, where its fostering could significantly contribute to the local agricultural development [9,10] and the development of parallel resources (such as power generation from agro-waste), in line with current European agricultural policies and regional energy master-plan [11-13].

The olive agro-industrial sector is of major economic importance throughout Sicily and the Mediterranean. Sicilian annual olive oil production totals about 47,000 t from about 315,000 t of olives [14]. As a result, more than 268,000 t of OME are produced as a by-product, which could potentially be converted into a low cost solid biofuel. Each of the 700 olive oil mills in Sicily produces on average $382 \mathrm{t}$ of OME.

Boasting some 158,000 ha of cultivated land and $€ 188$ million of revenue olives destined to the olive oil production. Olive oil is one of the main agricultural productions [14]. Nonetheless the disposal of OME has always been an issue for Sicilian olive oil sector. Traditionally, producers have disposed of by-products by selling OME to the husk-oil industry. However, nowadays, modern olive oil extraction techniques render husk-oil extraction less and less economic.

In addition to this, in recent years, the husk-oil market is contracting significantly and selling OME has gradually become more difficult. Hence, while in the past years the disposal of OME was a revenue source, nowadays it has become a significant problem for almost all olive oil mills. Olive oil producers are obliged to dispose of OME by spreading it on considerable areas of fields, thereby incurring in significant costs. 
While is not proven that OME can be used as a fertilizer or as a soil conditioner, the legislation which regulates OME disposal is becoming more and more stringent [15]. High volumes of OME need to be disposed of yearly, whilst suitable land is becoming ever less available. As a consequence, olive oil producers are often obliged to reduce the OME volume by drying the sludge: a high energy consumption process.

On the other hand, bioenergies offer today a valid alternative for OME disposal. In fact OME could be used as a low cost biofuel for renewable energy production, allowing farmers access to a renewed source of revenue. However, the energy conversion of OME is somewhat problematic due to its high humidity content and its high seasonality. OME are mainly composed of a perishable sludge showing in excess of $50 \%$ humidity content and their production is concentrated in only two or three months each year.

In Sicily, the total yearly olive oil production and hence the OME production is concentrated between October and December, with a high peak during the month of November. This seasonality coupled to the perishability of the material causes significant problems in the disposal of the residual biomass.

Moreover, according to Italian legislation, OME are considered a hazardous residue when they are not disposed of within five days of their production. Operators are then obliged to dispose of the OME within 5 days [16]. In this scenario, a process aimed at sustainable energy conversion of OME is a significant potential solution towards overall sustainability of olive cultivation. In particular, OME energy conversion could transform a potential problem into a virtuous renewable energy production process.

Power generation from agro-waste is particularly interesting for some agricultural areas of Sicily, where this practice could significantly contribute to the local agricultural development, in line with current European agricultural policies [17].

Nonetheless, as explained, OME are unsuitable to energy conversion if used as they come out of the oil mill. Stabilization is thereby needed to preserve energy characteristics of the by-product and to allow storage throughout the year.

In this study, a three-stage stabilization process is foreseen: (1) oven drying; (2) fine milling and (3) densification by means of pelletisation. As mentioned, feedstock stabilisation is a necessary process in order to make use of OME for energy production, however, the process is potentially highly energy consuming. Yet, the amount of energy needed to fully stabilize the feedstock is not known and there is effectively no information about the issue on academic literature.

For this reason, this study attempts at a thorough evaluation of the energy consumption of a three stages stabilization process, this information is crucial to assess OME suitability for energy conversion.

\section{Experimental Setup and Procedure}

The experimental analysis was conducted through four stages:

- Sample drying: evaluation of feedstock humidity content;

- Sample milling: evaluation of energy consumption;

- Sample pelletisation: evaluation of energy consumption during the process; 
- Sample combustion: determination of High Calorific Value (HCV) and Low Calorific Value (LCV).

The analyses have been conducted in compliance with the ASTM and UNI standards as per the following list:

- Sample Preparation: Standards CEN/TS 14778-1, CEN/TS 14779, CEN/TS 14780, UNI 9903-3;

- Humidity content: Standards CEN/TS 14774-1, CEN/TS 14774-2, CEN/TS 14774-3;

- Ashes: CEN/TS 14775.

Samples were collected during the months of November and December at three different milling farms, located in North-West Sicily. Each sample weighed approximately $20 \mathrm{~kg}$ and was composed of $50 \%$ Nocellara del Belice and 50\% Biancolilla, two varieties particularly common in Sicily.

Two of the olive farms produced olive sludge (mix of husk and pulp), the other was equipped with a husk separator, hence two samples, one of olive pulp and the other of olive husk were collected from mill No. 4. In total No. 4 samples were collected: two samples of sludge weighing each $20 \mathrm{~kg}$ each from mill No. 1 and 2 and two samples weighing $20 \mathrm{~kg}$ each of pulp and husk from mill No. 3 .

The samples collected from the olive mill farms were used as a base for sampling of all the analyses conducted. In order to prevent oxidation during laboratory analyses, the samples were stored in PVC dark and airtight containers.

The evaluation of humidity content was conducted by means of thermogravimetric analysis using a lab analyser LECO TGA-701 (see Figure 1), able to evaluate humidity content, ashes and volatile matter.

Figure 1. Carousel of the LECO TGA-701 thermogravimetric analyser.

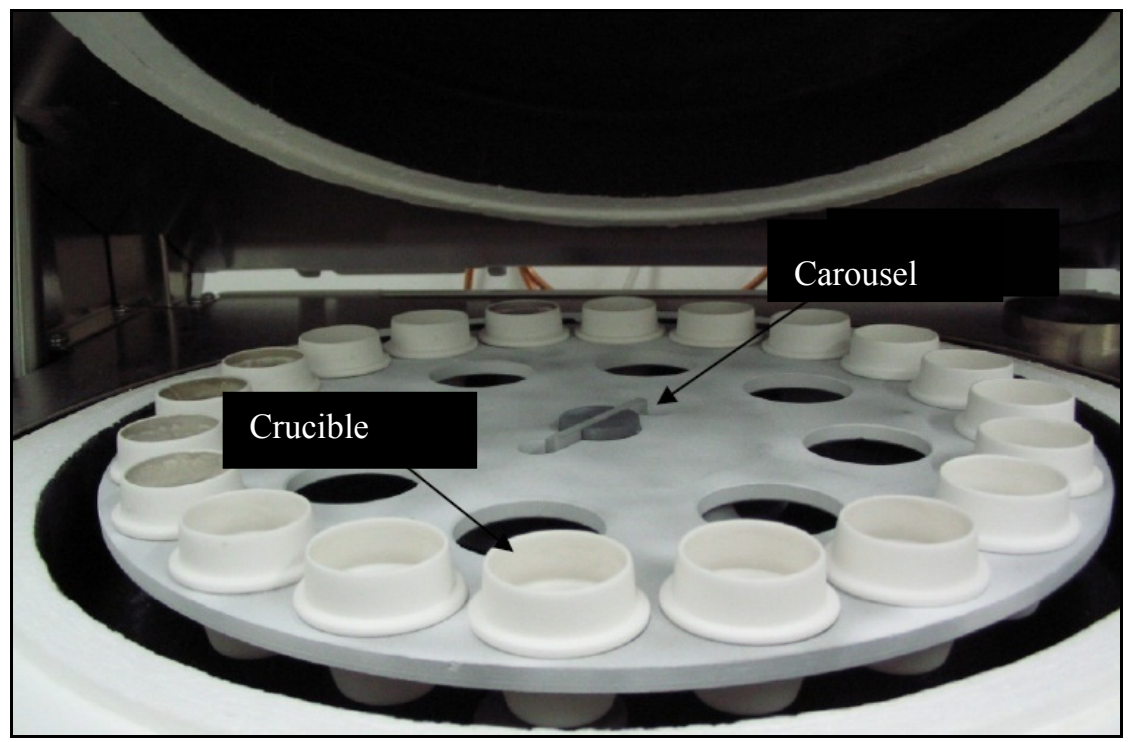

The samples are kept in a closed oven were atmosphere and temperature are controlled and monitored. During the drying process, the temperature is kept at $102{ }^{\circ} \mathrm{C}$ and weight of samples is continuously monitored. The instrument houses a Sartorious $0.0001 \mathrm{~g}$ precision scale. 
No. 4 samples were collected from each of the three olive mill farms; No. 3 replicas were analysed for each of the samples. The trial was conducted in compliance with norms CEN/TS 15148 and 14775. Volatile substances were evaluated using standard UNI 9903-3.

The humidity content allows evaluation of the energy necessary to drying the feedstock, that is the energy necessary to evaporate the amount of water present in each sample, at ambient pressure. Once the humidity content and the latent heat of vaporization at ambient pressure are known, the heat necessary for drying the sample can be calculated. Assuming that the drying heat is produced by burning an adequate amount of the same feedstock, the equivalent electrical energy loss can be calculated as the "missed production" of electrical energy due to the consumption of feedstock. This value can be calculated once the LCV of the feedstock is known.

Dried samples were then finely milled to evaluate the energy required for milling. Samples, weighting approximately $40 \mathrm{~g}$ were finely milled ( $1 \mathrm{~mm}$ particle size) by means of a Retsch Type ZM1 $\mathrm{N}^{\circ} 29907$ laboratory mill equipped with a $600 \mathrm{~W}$ power electrical engine. The amount of electrical energy consumed during the milling process was then calculated by timing the process using a digital chronometer. The time multiplied by the mill power enabled calculation of the energy consumed during the process with the formula:

$$
E=P_{\text {mill }} \times t
$$

where $P_{\text {mill }}$ is the mill power in Watt; $t$ is the milling time in seconds.

After milling, the feedstock has been densified by means of a pelletiser. No. 3 samples of fresh feedstock, weighing $5 \mathrm{~kg}$ each, were dried to $12 \%$ humidity content and finely milled by means of a Retsch Type ZM1 No 29907 mill. No. 3 replicas per each dried and milled sample were pelletised using three different small size pelletisers, of the type normally employed for domestic uses or small industrial scale. A brief description of the three pelletisers and their characteristics is described below.

\section{Pelletiser No. 1: "Bremana"}

This is a professional pelletiser used for small and medium size carpentries. This machine is normally used to produce densified biofuel from saw dust and other wood residues. The machine is equipped with a $4 \mathrm{~kW}$ electrical engine. This machine is able to produce pellets of $6 \mathrm{~mm}$ diameter at a $40-60 \mathrm{~kg} / \mathrm{h}$ on a continuous basis. The inlet humidity content must be $15 \%$ maximum.

\section{Pelettiser No. 2: "Pellettina"-Macpellet}

This pelletiser is equipped with a $5.5 \mathrm{~kW}$ electrical engine. It is used to produce pellets from saw dust and agricultural residues. Production rates are approximately $120 \mathrm{~kg} / \mathrm{h}$. The machine is equipped to produce $6 \mathrm{~mm}$ width pellets.

\section{Pelletiser No. 3: SKJ200 Electric Pelletiser}

This pelletiser is motorised with a $7.5 \mathrm{~kW}$ engine, is able to produce $6 \mathrm{~mm}$ diameter pellets and production is around $120 \mathrm{~kg} / \mathrm{h}$.

No. 12 dried and finely milled samples of $5 \mathrm{~kg}$ weight each were collected and pelletised, 4 per each of the described machines. The electrical energy consumed was calculated using the formula:

$$
E=P_{\text {pellet }} \times t
$$


where $P_{\text {pellet }}$ is the pellettiser power in Watt; $t$ is the pelletising time in seconds.

Average values per each of the machines where calculated and the three values, one per each of the pelletiser, were then averaged again to evaluate the net electrical energy consumed for densification of biomass.

The evaluation of HCV was performed using an isoperibolic method, using measures that comply with the standards and procedure described in CEN/TS14775. Densified samples weighing approximately $1 \mathrm{~g}$ were burned in a LECO AC-350 calorimeter, to evaluate the HCV. The LCV was then calculated by subtracting the energy released by condensation of the intrinsic water contained in the samples. Intrinsic water content is calculated once the amount of hydrogen contained in the samples is known. Hydrogen content was calculated by means of a Carbon, Hydrogen, Nitrogen (CHN) analysis conducted with a LECO Truspec CHN instrument (see Figure 2).

Figure 2. (a) Manual press used to produce pellet for the calorimetric analysis; (b) LECO Truspec CHN analyser carousel.
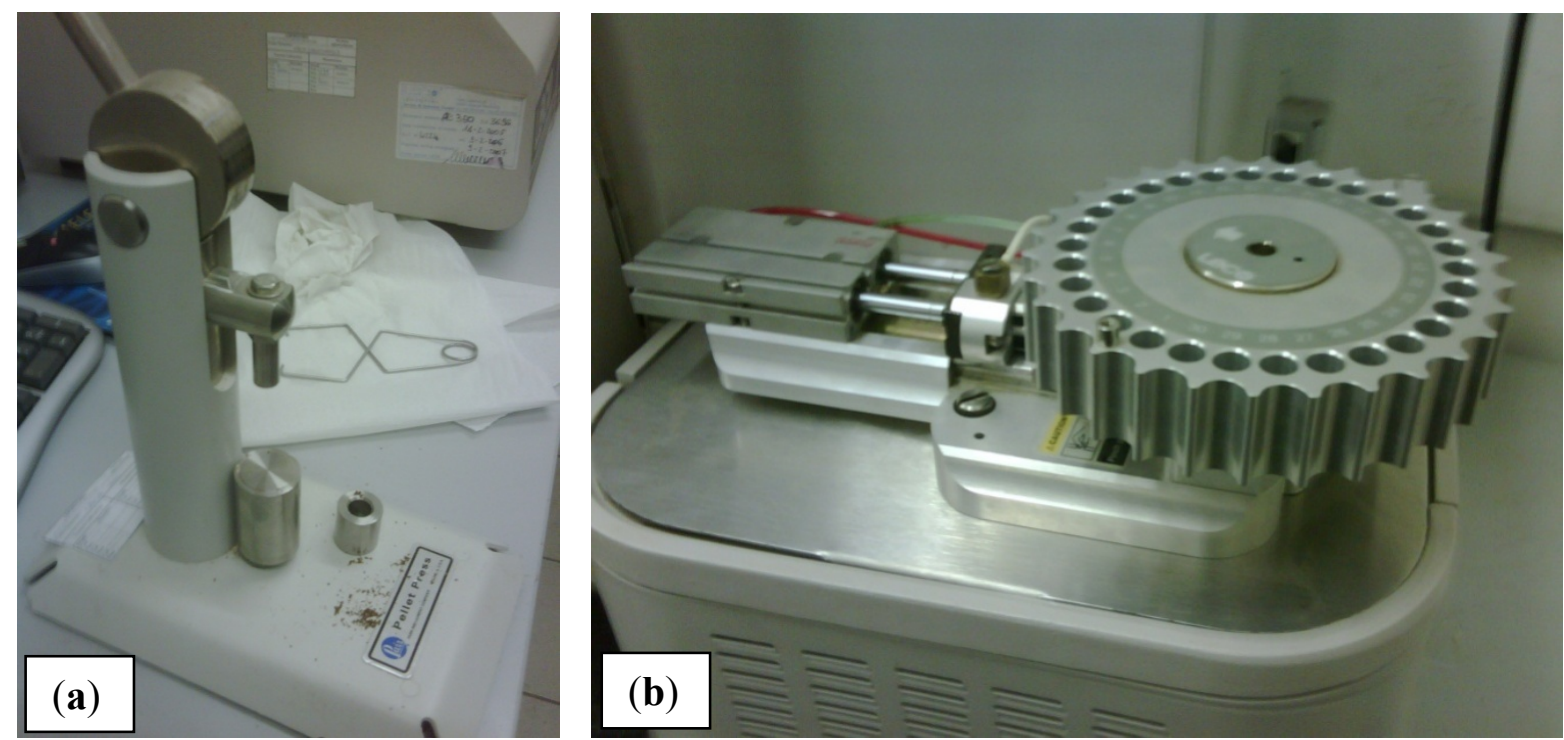

No. 3 replicas were analysed per each sample, each weighing approximately $0.35 \mathrm{~g}$. The measures are conducted complying with ASTM D 5373. The heat released by condensation of this water is evaluated as the latent vaporization heat of water at ambient pressures multiplied by the amount of intrinsic water contained in the samples.

The net electrical energy available from a unit mass of OME, is calculated as the difference between the electrical energy obtainable by the LCV and the electrical energy consumed per each of the stabilization phases. The data calculated per each of the stabilization phases were converted into equivalent electric energy loss. The net available electrical energy was calculated per the following formula:

$$
E_{\text {net }}=E_{L C V}-E_{\text {drying }}-E_{\text {milling }}-E_{\text {pelletising }}
$$

where $E_{n e t}$ is the net electrical energy potentially obtainable by the unit of biomass; $E_{L C V}$ is the electrical energy potentially available from direct combustion of feedstock and energy conversion in a ORC turbine; $E_{\text {drying }}$ is the equivalent electrical energy lost in drying the unit of biomass, calculated as 
the energy necessary to remove all the feedstock humidity, based upon the latent heat of water vaporization at atmospheric pressure, assuming that an appropriate amount of the same biomass is consumed to produce enough thermal energy to drying the feedstock. The electrical energy loss is calculated as the electrical energy production theoretically obtainable by the biomass used for drying purposes; $E_{\text {milling }}$ is the electrical energy directly consumed for milling $1 \mathrm{~kg}$ of biomass; $E_{\text {pelletising }}$ is the electrical energy directly consumed for pelletising a $\mathrm{kg}$ of biomass.

The experimental data obtained were statistically tested with a variance analysis (ANOVA). The average values were tested through Duncan Test, with $p$ value equal to 0.05 . In other words, when average values of a number of replicas of a sample would differ from average values of replicas of another sample in more than $95 \%$ of the cases, the difference was considered statistically significant, when, instead, the average values of the replicas would differ in less than $95 \%$ of the cases, the difference was considered statistically not significant.

\section{Results and Discussion}

\subsection{Drying}

The energy necessary to dry the water contained in the samples was determined from the latent heat of vaporization (LHV) at ambient pressure, assumed to be $2272 \mathrm{~J} / \mathrm{g}$. Table 1 shows the water content calculated for each of the samples, alongside with the weight losses. Humidity content was sensibly higher for olive pulp, which showed an average 58.14\% weight loss during the tests; the sludge showed lower values, on average $46.66 \%$ and $48.41 \%$ weight loss for mill No. 1 and mill No. 2 respectively. As expected, olive husk showed the lowest value, some $12.03 \%$ weight loss.

Table 1. Humidity content evaluated per each of the replicates.

\begin{tabular}{ccccccc}
\hline Olive mill & Replica & $\begin{array}{c}\text { Weight humid } \\
\text { [g] }\end{array}$ & $\begin{array}{c}\text { Dry Weight } \\
\text { [g] }\end{array}$ & $\begin{array}{c}\text { Humidity } \\
\text { content [g] }\end{array}$ & $\begin{array}{c}\text { Weight loss } \\
\text { [\%] }\end{array}$ & $\begin{array}{c}\text { Average } \\
\text { weight loss [\%] }\end{array}$ \\
\hline \multirow{2}{*}{ No.1 } & I & 8.8473 & 4.7605 & 4.0868 & $46.19 \%$ & \\
Sludge & II & 9.171 & 4.9678 & 4.2032 & $45.83 \%$ & $46.66 \%$ \\
& III & 9.3721 & 4.8782 & 4.4939 & $47.95 \%$ & \\
No.2 & I & 8.0315 & 4.2285 & 3.803 & $47.35 \%$ & \\
Sludge & II & 9.0817 & 5.163 & 3.9187 & $43.15 \%$ & $48.41 \%$ \\
& III & 8.5512 & 3.8723 & 4.6789 & $54.72 \%$ & \\
No.3 & I & 9.4184 & 3.9614 & 5.457 & $57.94 \%$ & \\
Pulp & II & 9.8379 & 4.0165 & 5.8214 & $59.17 \%$ & $58.14 \%$ \\
& III & 9.287 & 3.9658 & 5.3212 & $57.30 \%$ & \\
No.3 & I & 8.0526 & 7.1125 & 0.9401 & $11.67 \%$ & \\
Husk & II & 9.5734 & 8.4567 & 1.1167 & $11.66 \%$ & $12.03 \%$ \\
& III & 9.0708 & 7.9134 & 1.1574 & $12.76 \%$ & \\
\hline
\end{tabular}


Table 2 shows the calculation to evaluate the thermal energy loss for drying the sample. Statistical analysis showed that the differences between the two sludge samples were not relevant, whilst differences between the sludge results and the pulp and between the pulp and the husk samples were relevant. Figure 3 shows the differences among the calculated value.

Table 2. Thermal energy loss for drying the samples.

\begin{tabular}{cccccc}
\hline Sample & Replica & $\begin{array}{c}\text { Water content } \\
\text { [g] }\end{array}$ & $\begin{array}{c}\text { Heat loss } \\
{[\mathbf{J}]}\end{array}$ & $\begin{array}{c}\text { Unit heat loss } \\
{[\mathbf{k J} / \mathbf{k g}]}\end{array}$ & $\begin{array}{c}\text { Average per } \\
\text { replicas [kJ/kg] }\end{array}$ \\
\hline \multirow{2}{*}{ No.1 } & I & 4.0868 & $9,285.21$ & 1950.47 & \\
Sludge & II & 4.2032 & $9,549.67$ & 1922.31 & 1988.6 \\
& III & 4.4939 & $10,210.14$ & 2093.01 & \\
No.2 & I & 3.803 & $8,640.42$ & 2043.38 & \\
Sludge & II & 3.9187 & $8,903.29$ & 1724.44 & 2171.02 \\
& III & 4.6789 & $10,630.46$ & 2745.26 & \\
No.3 & I & 5.457 & $12,398.3$ & 3129.78 & 3157.09 \\
Pulp & II & 5.8214 & $13,226.22$ & 3292.97 & \\
& III & 5.3212 & $12,089.77$ & 3048.51 & 310.87 \\
No.3 & I & 0.9401 & $2,135.91$ & 300.3 & \\
Husk & II & 1.1167 & $2,537.14$ & 300.02 & \\
& III & 1.1574 & $2,629.61$ & 332.3 & \\
\hline
\end{tabular}

Figure 3. Average heat loss.

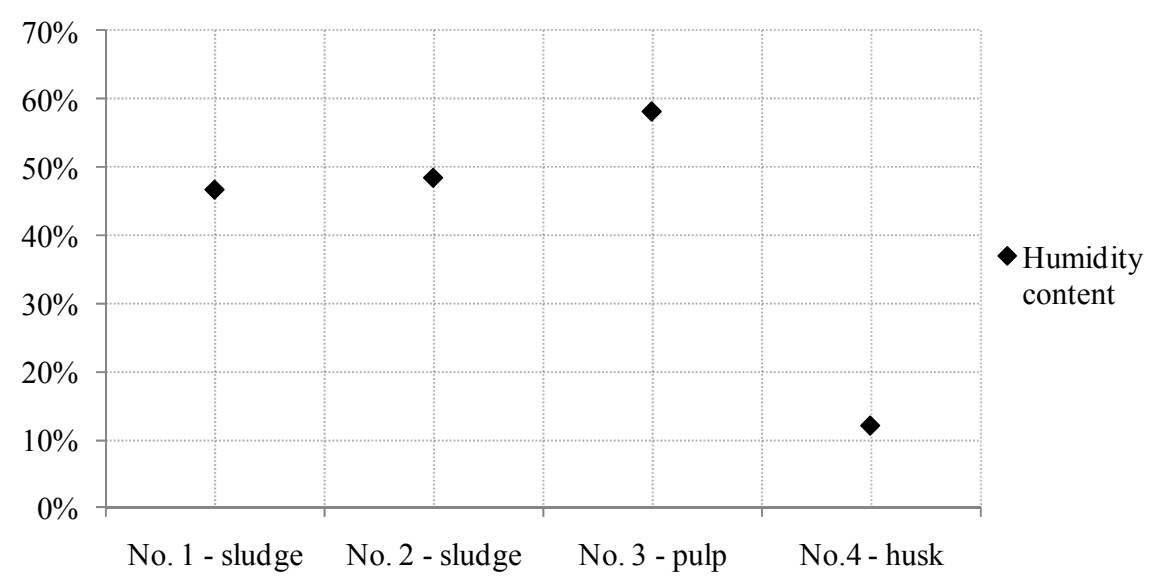

\subsection{Milling}

Table 3 shows the electrical energy consumption calculated per each of the replicas of the four samples. The data show some differences among the different samples. Husk showed the highest value while pulp showed the lowest. As expected, the sludge showed values in between the other two, in line with the expected mix of husk and pulp in the sludge. Differences between sludge and husk and between sludge and pulp were statistically relevant, while differences between the two sludge samples were not relevant. 
Table 3. Milling energy consumption.

\begin{tabular}{ccccccc}
\hline $\begin{array}{c}\text { Olive } \\
\text { Mill }\end{array}$ & Replica & $\begin{array}{c}\text { Weight } \\
\text { [g] }\end{array}$ & $\begin{array}{c}\text { Milling } \\
\text { time [s] }\end{array}$ & $\begin{array}{c}\text { Electrical energy for } \\
\text { milling [J] }\end{array}$ & $\begin{array}{c}\text { Specific electrical } \\
\text { energy [kJ/kg] }\end{array}$ & $\begin{array}{c}\text { Average electrical } \\
\text { energy [kJ/kg] }\end{array}$ \\
\hline \multirow{2}{*}{ No.1 } & I & 33.5269 & 26.67 & 16.002 & 477.29 & \\
Sludge & II & 43.3809 & 23.75 & 14.250 & 328.49 & 408.57 \\
& III & 42.1345 & 29.49 & 17.694 & 419.94 & \\
No.2 & I & 41.3869 & 28.97 & 17.382 & 419.99 & 398.02 \\
Sludge & II & 41.2399 & 28.46 & 17.076 & 414.07 & \\
& III & 42.3498 & 25.41 & 15.246 & 360.00 & 128.01 \\
No.3 & I & 40.1456 & 8.03 & 4.818 & 120.01 & \\
Pulp & II & 41.3839 & 9.52 & 5.712 & 138.02 & \\
& III & 41.0019 & 8.61 & 5.166 & 125.99 & 789.97 \\
No.3 & I & 42.8521 & 59.56 & 35.736 & 833.94 & \\
Husk & II & 40.0984 & 52.13 & 31.278 & 780.03 & \\
\hline
\end{tabular}

Statistical analysis showed that the differences between the two sludge samples were not relevant, whilst differences between the sludge and the pulp and between the pulp and the husk were relevant.

\subsection{Pelletisation}

Table 4 shows the electrical energy consumptions for the three pelletisers used in tests, alongside with average values.

Table 4. Energy consumption for pelletisation of samples.

\begin{tabular}{cccccccc}
\hline $\begin{array}{c}\text { Olive } \\
\text { Mill }\end{array}$ & Replica & $\begin{array}{c}\text { Weight } \\
{[\mathbf{g}]}\end{array}$ & $\begin{array}{c}\text { Brembana } \\
{[\mathbf{k J} / \mathbf{k g}]}\end{array}$ & $\begin{array}{c}\text { Pellettina- } \\
\text { Macpellet } \\
{[\mathbf{k J} / \mathbf{k g}]}\end{array}$ & $\begin{array}{c}\text { SKJ200 } \\
\text { Elettrica } \\
{[\mathbf{k J} / \mathbf{k g}]}\end{array}$ & $\begin{array}{c}\text { Average } \\
\text { among } \\
\text { pelletisers } \\
{[\mathbf{k J} / \mathbf{k g}]}\end{array}$ & $\begin{array}{c}\text { Average } \\
\text { values } \\
{[\mathbf{k J} / \mathbf{k g}]}\end{array}$ \\
\hline No.1 & I & 4948.67 & 288 & 219.6 & 230 & 246.00 & \\
Sludge & II & 5222.00 & 277.2 & 291.6 & 292 & 286.80 & 264.40 \\
& III & 5218.33 & 298.8 & 241.2 & 241 & 260.40 & \\
No.2 & I & 5169.67 & 280.8 & 295.2 & 281 & 285.60 & \\
Sludge & II & 4493.33 & 324 & 295.2 & 270 & 296.40 & 284.40 \\
& III & 5283.33 & 324 & 244.8 & 245 & 271.20 & \\
No.3 & I & 5514.33 & 270 & 234 & 313 & 272.40 & \\
Pulp & II & 4645.33 & 252 & 313.2 & 306 & 290.40 & 259.60 \\
& III & 4841.33 & 216 & 212.4 & 220 & 216.00 & \\
No.3 & I & 5335.33 & 259.2 & 298.8 & 292 & 283.20 & \\
Husk & II & 4897.00 & 248,4 & 331.2 & 324 & 301.20 & 287.60 \\
\hline
\end{tabular}

Data obtained did not show statistically relevant differences between sludge samples and pulp samples. Values obtained for the husk samples showed relevant differences with all the other values. 


\subsection{High Calorific Value (HCV), Hydrogen Content and Low Calorific Value}

Table 5 shows the calculated values for HCV for all the samples. The sludge and pulp samples showed similar values, whilst the husk sample showed a considerably lower value. This is due to the presence of oil in the pulp.

Table 5. Evaluation of HCV.

\begin{tabular}{ccccc}
\hline Olive Mill & Replica & Weight $[\mathbf{g}]$ & HCV $[\mathbf{J} / \mathbf{g}]$ & Average HCV [J/g] \\
\hline \multirow{2}{*}{ No.1 } & I & 1.0186 & 25,169 & \\
Sludge & II & 1.0061 & 25,192 & 25,121 \\
& III & 1.0369 & 25,003 & \\
No.2 & I & 1.1896 & 25,103 & 25,128 \\
Sludge & II & 1.0769 & 25,148 & \\
& III & 1.0737 & 25,134 & 25,410 \\
No.3 & I & 0.8679 & 25,433 & \\
Pulp & II & 0.8725 & 25,535 & \\
& III & 0.9451 & 25,262 & 20,461 \\
No.3 & I & 0.8952 & 20,353 & \\
Husk & II & 0.5187 & 20,831 & \\
\hline
\end{tabular}

This result shows the benefits of using olive sludge as opposed to olive husk as a biofuel, the second is more traditionally used as biofuel, but substantially less useful in terms of energy available. Table 6 shows hydrogen content, number of moles of water and calculated loss of calorific value, necessary to evaluate the LCV starting from HCV.

Table 7 shows values for HCV and LCV.

Table 6. Loss of Calorific Value due to presence of intrinsic water.

\begin{tabular}{ccccccccc}
\hline Sample & Replica & $\begin{array}{c}\text { Weight } \\
\text { [g] }\end{array}$ & $\begin{array}{c}\text { Hydrogen } \\
{[\mathbf{\%}]}\end{array}$ & $\begin{array}{c}\text { Weight } \\
\text { of } \mathbf{H}[\mathbf{g}]\end{array}$ & $\begin{array}{c}\text { Moles } \\
\text { of } \mathbf{H}_{\mathbf{2}} \mathbf{O} \\
{[\mathbf{N o} \text {.] }}\end{array}$ & $\begin{array}{c}\text { Weight } \\
\text { of } \mathbf{H}_{\mathbf{2}} \mathbf{O} \\
{[\mathbf{g}]}\end{array}$ & $\begin{array}{c}\text { Energy } \\
\text { released by } \\
\text { condensation } \\
\text { of water }[\mathbf{J}]\end{array}$ & $\begin{array}{c}\text { Loss of } \\
\text { Calorific } \\
\text { Value } \\
{[\mathbf{J} / \mathbf{g}]}\end{array}$ \\
\hline No.1 & I & 0.2279 & 7.5067 & 0.0171 & 0.0085 & 0.1529 & 347.35 & 1524.14 \\
sludge & II & 0.1802 & 7.539 & 0.0136 & 0.0067 & 0.1214 & 275.83 & 1530.7 \\
& III & 0.1844 & 7.593 & 0.0140 & 0.0069 & 0.1251 & 284.28 & 1541.66 \\
No.2 & I & 0.1723 & 7.638 & 0.0132 & 0.0065 & 0.1176 & 267.20 & 1550.8 \\
sludge & II & 0.1956 & 7.5776 & 0.0148 & 0.0074 & 0.1325 & 300.94 & 1538.54 \\
& III & 0.2054 & 7.6172 & 0.0156 & 0.0078 & 0.1398 & 317.67 & 1546.58 \\
No.3 & I & 0.1886 & 7.9044 & 0.0149 & 0.0074 & 0.1332 & 302.68 & 1604.89 \\
pulp & II & 0.1845 & 8.0721 & 0.0149 & 0.0074 & 0.1331 & 302.38 & 1638.94 \\
& III & 0.1857 & 7.9859 & 0.0148 & 0.0074 & 0.1325 & 301.1 & 1621.44 \\
No.3 & I & 0.3317 & 6.2414 & 0.0207 & 0.0103 & 0.1850 & 420.34 & 1267.24 \\
husk & II & 0.3578 & 6.2591 & 0.0224 & 0.0111 & 0.2001 & 454.7 & 1270.83 \\
& III & 0.3542 & 6.2753 & 0.0222 & 0.0110 & 0.1986 & 451.29 & 1274.12 \\
\hline
\end{tabular}


Table 7. Calculation of LCV.

\begin{tabular}{lccccc}
\hline Olive Mill & Replica & HCV [J/g] & $\begin{array}{c}\text { Energy released by } \\
\text { condensation of } \\
\text { intrinsic water [J] }\end{array}$ & LCV [J/g] & $\begin{array}{c}\text { Average LCV } \\
{[\mathbf{J} / \mathbf{g}]}\end{array}$ \\
\hline \multirow{2}{*}{ No.1 Sludge } & I & 25,169 & 1524.14 & 23,645 & \\
& II & 25,192 & 1530.70 & 23,661 & 23,589 \\
No.2 Sludge & III & 25,003 & 1541.66 & 23,461 & \\
& I & 25,103 & 1550.80 & 23,552 & \\
No.3 Pulp & II & 25,148 & 1538.54 & 23,609 & 23,788 \\
& III & 25,134 & 1546.58 & 23,587 & \\
No.3 Husk & I & 25,433 & 1604.89 & 23,828 & 19,190 \\
& III & 25,535 & 1638.94 & 23,896 & \\
\hline
\end{tabular}

As per the $\mathrm{HCV}$, there is no statistically significant difference between the values of the sludge samples, and between the sludge samples and the pulp sample. Whilst statistically significant differences are shown between the value for husk and the other values, husk showed considerably lower energy content. The values of electrical energy available from feedstock are shown on Table 8 , alongside with the residual thermal energy.

Table 8. Available electrical and thermal energy.

\begin{tabular}{lccccc}
\hline \multicolumn{1}{c}{ Sample } & $\begin{array}{c}\text { Average } \\
\text { LCV [J/g] }\end{array}$ & $\begin{array}{c}\text { Turbine electrical } \\
\text { efficiency [\%] }\end{array}$ & $\begin{array}{c}\text { Losses } \\
{[\%]}\end{array}$ & $\begin{array}{c}\text { Electrical Energy } \\
\text { available [kJ/kg] }\end{array}$ & $\begin{array}{c}\text { Thermal energy } \\
\text { available [J/g] }\end{array}$ \\
\hline No.1 Sludge & 23,589 & $24 \%$ & $3 \%$ & 5661.40 & 17,220 \\
No.2 Sludge & 23,583 & $24 \%$ & $3 \%$ & 5659.93 & 17,215 \\
No.3 Pulp & 23,788 & $24 \%$ & $3 \%$ & 5709.18 & 17,365 \\
No.3 Husk & 19,190 & $24 \%$ & $3 \%$ & 4605.66 & 14,008 \\
\hline
\end{tabular}

Once the LCV of the feedstock is known, the amount of biomass necessary to dry the feedstock can be calculated, so is the "missed" electric energy production. Table 9 shows the values for electrical energy loss for drying one $\mathrm{kg}$ of feedstock.

Table 9. Missed electrical energy production.

\begin{tabular}{lccccc}
\hline Olive Mill & $\begin{array}{c}\text { LCV } \\
{[\mathbf{k J} / \mathbf{k g}]}\end{array}$ & $\begin{array}{c}\text { Heat needed } \\
\text { for drying } \\
{[\mathbf{k J} / \mathbf{k g}]}\end{array}$ & $\begin{array}{c}\text { Amount of } \\
\text { feedstock necessary } \\
\text { for drying }\end{array}$ & $\begin{array}{c}\text { Electrical energy } \\
\text { obtainable from } \\
\text { feedstock }[\mathbf{k J} / \mathbf{k g}]\end{array}$ & $\begin{array}{c}\text { Missed electrical } \\
\text { energy production } \\
{[\mathbf{k J} / \mathbf{k g}]}\end{array}$ \\
\hline No.1 Sludge & 23,589 & 1988.60 & 0.08 & 5661.40 & 477.26 \\
No.2 Sludge & 23,583 & 2171.02 & 0.09 & 5659.93 & 521.05 \\
No.3 Pulp & 23,788 & 3157.09 & 0.13 & 5709.18 & 757.70 \\
No.3 Husk & 19,190 & 310.87 & 0.02 & 4605.66 & 74.61 \\
\hline
\end{tabular}




\subsection{Energy Balance}

Table 10 shows the energy balance for feedstock, alongside with the results of the statistical analysis. Values coupled with the same letters showed no statistically significant differences. The results show that some $1150 \mathrm{~kJ}$ are consumed for stabilising the feedstock, and no statistically significant difference among values for sludge, pulp or husk. The latter shows a considerably lower energy consumption for drying, but this energy saving is consumed for milling the feedstock. Overall, sludge and pulp show the highest net available energy, and no statistically significant difference among the calculated values, while husk shows considerably lower figure.

Table 10. Electrical energy balance.

\begin{tabular}{|c|c|c|c|c|c|c|c|c|c|c|c|c|}
\hline \multirow{2}{*}{$\begin{array}{c}\text { Sample } \\
\\
\text { No.1 } \\
\text { Sludge }\end{array}$} & \multicolumn{2}{|c|}{$\begin{array}{c}\text { Electrical } \\
\text { Energy } \\
\text { available } \\
{[\mathrm{kJ} / \mathrm{kg}]}\end{array}$} & \multicolumn{2}{|c|}{$\begin{array}{c}\text { Missed } \\
\text { electrical } \\
\text { energy for } \\
\text { drying } \\
\text { [kJ/kg] }\end{array}$} & \multicolumn{2}{|c|}{$\begin{array}{c}\text { Milling } \\
\text { electrical } \\
\text { energy } \\
{[\mathbf{k J} / \mathbf{k g}]}\end{array}$} & \multicolumn{2}{|c|}{$\begin{array}{c}\text { Pelletising } \\
\text { electrical } \\
\text { energy } \\
{[\mathbf{k J} / \mathbf{k g}]}\end{array}$} & \multicolumn{2}{|c|}{$\begin{array}{c}\text { Stabilisation } \\
\text { energy } \\
\text { consumption } \\
{[\mathrm{kJ} / \mathrm{kg}]}\end{array}$} & \multicolumn{2}{|c|}{$\begin{array}{c}\text { Net available } \\
\text { electrical } \\
\text { energy } \\
\text { [kJ/kg] }\end{array}$} \\
\hline & 5661.40 & $\mathrm{a}$ & 477.26 & $\mathrm{a}$ & 408.57 & $\mathrm{a}$ & 264.40 & $\mathrm{a}$ & 1150.24 & $\mathrm{a}$ & 4511.16 & $\mathrm{a}$ \\
\hline $\begin{array}{c}\text { No.2 } \\
\text { Sludge }\end{array}$ & 5659.93 & $\mathrm{a}$ & 521.05 & $\mathrm{a}$ & 398.02 & $\mathrm{a}$ & 284.40 & $\mathrm{a}$ & 1203.46 & $\mathrm{a}$ & 4456.47 & $\mathrm{a}$ \\
\hline $\begin{array}{l}\text { No.3 } \\
\text { Pulp }\end{array}$ & 5709.18 & $\mathrm{a}$ & 757.70 & b & 128.01 & $\mathrm{~b}$ & 259.60 & $\mathrm{a}$ & 1145.31 & $\mathrm{a}$ & 4563.87 & $\mathrm{a}$ \\
\hline $\begin{array}{l}\text { No.3 } \\
\text { Husk }\end{array}$ & 4605.66 & b & 74.61 & c & 789.97 & $\mathrm{c}$ & 287.60 & $\mathrm{a}$ & 1152.18 & $\mathrm{a}$ & 3453.48 & $\mathrm{~b}$ \\
\hline
\end{tabular}

Values coupled with the same letters showed no statistically significant differences.

Figure 4 shows the same values. Pelletising energy is substantially equal for all the samples, milling energy is lower for pulp and higher for husk, on the contrary, the latter requires less energy for drying. Energy balance is shown in Figure 5.

Figure 4. Energy consumption for stabilization of feedstock.

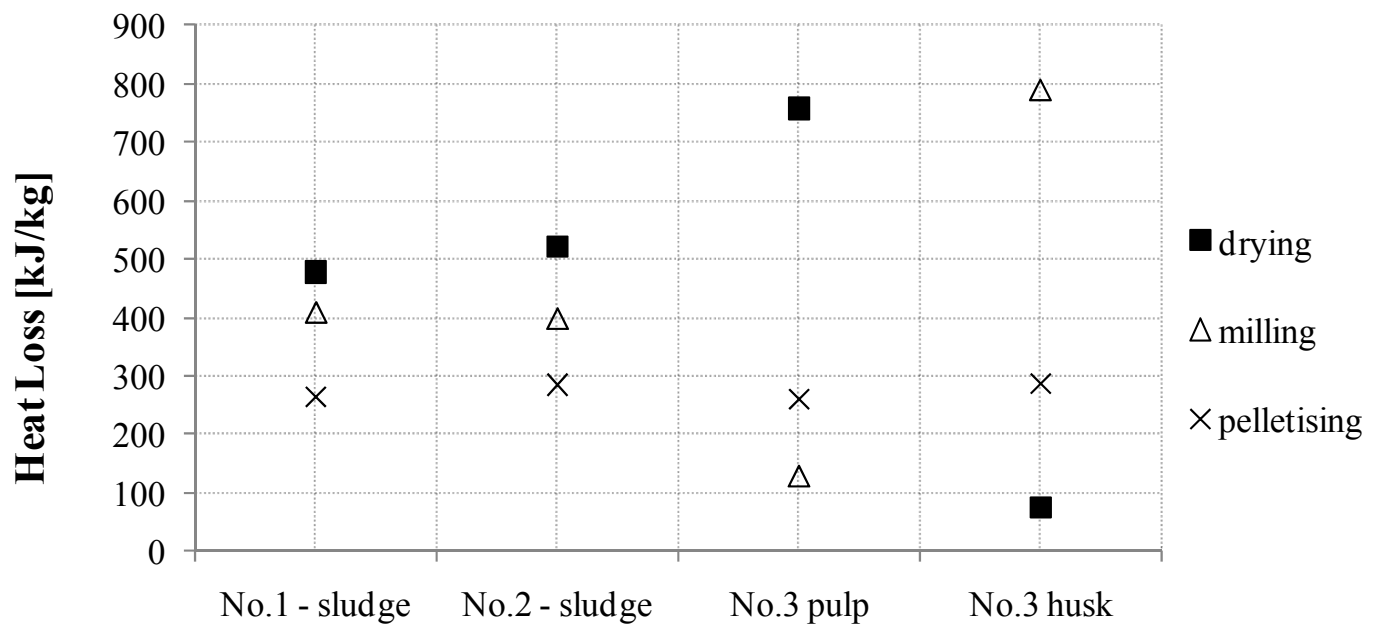


Figure 5. Energy balance.

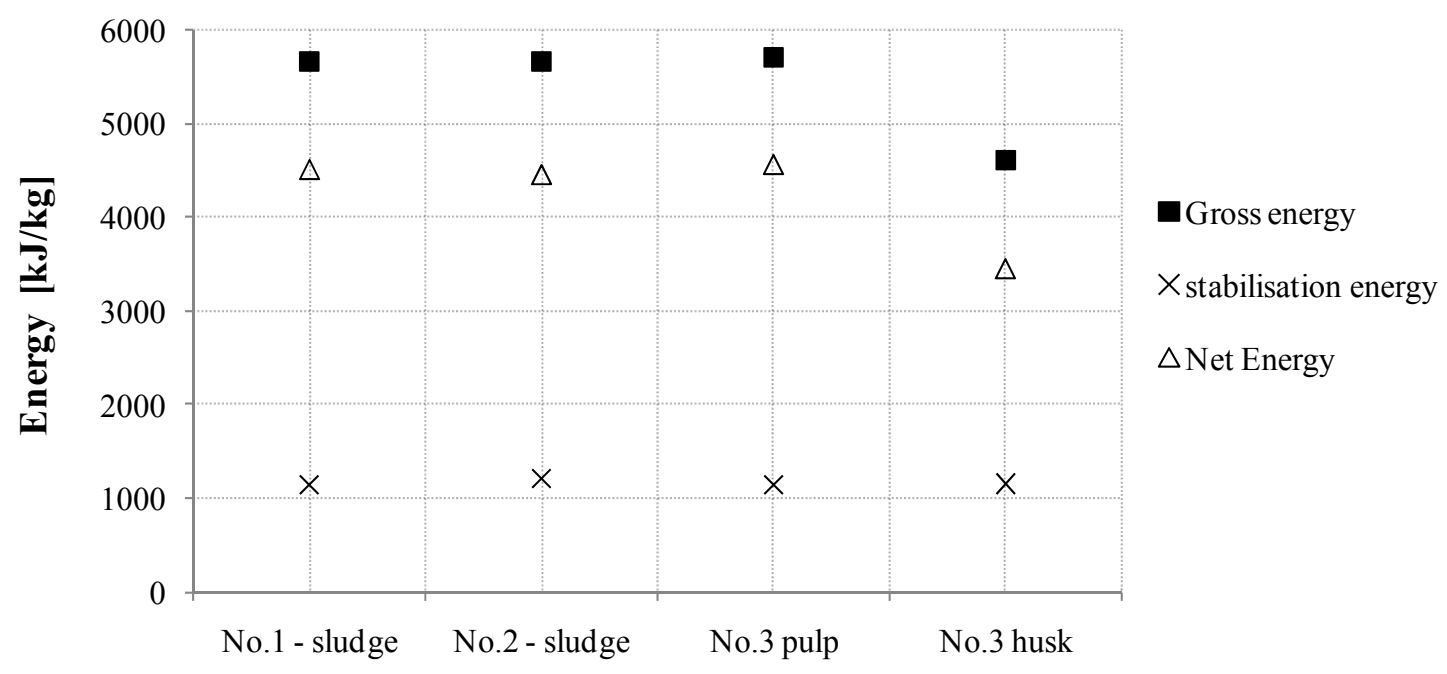

\section{Conclusions}

This study demonstrates that OME can be used as feedstock for renewable energy production. In particular, this research shows that a three-stage OME stabilization process based on densification is sustainable with regards to the energy consumption of the process itself and the gross electrical energy obtainable from direct combustion of the biomass. Results show that OME sludge (a mix of pulp and husk) and pulp only may potentially produce some $5600-5700 \mathrm{~kJ} / \mathrm{kg}$ of dried substance, while olive husk has a gross energy content a little above $4600 \mathrm{~kJ} / \mathrm{kg}$.

Moreover, tests demonstrate that olive pulp and sludge show similar net available energy, approximately $4500 \mathrm{~kJ} / \mathrm{kg}$, while husk shows only $3400 \mathrm{~kJ} / \mathrm{kg}$ net energy. This suggests that, from an energy content point of view, OME sludge is an appropriate feedstock for biomass based energy production and that a three stage stabilization line for an OME based energy chain is foreseeable. This would allow a virtuous cycle at the olive mill level or small groups of olive mills, making good use of a residue, while simultaneously eliminating a waste disposal problem.

\section{Acknowledgements}

This research was carried out in the framework of the scientific collaboration agreement between University of Enna Kore and Enel Group S.p.A.

\section{References}

1. Sanders, J.; Van Der Hoeven, D. Opportunities for a Bio-based Economy in the Netherlands. Energies 2008, 1, 105-119.

2. Koseki, H. Evaluation of Various Solid Biomass Fuels Using Thermal Analysis and Gas Emission Tests. Energies 2011, 4, 616-627.

3. Antolìn, G.; Irusta, R.; Velasco, E.; Carrasco, J.; Gonzàlez, E.; Ortìz, L. Biomass as an energy resource in Castilla y Leon (Spain). Energy 1996, 21, 165-172. 
4. Fernandes, U.; Costa, M. Potential of biomass residues for energy production and utilization in a region of Portugal. Biomass Bioenergy 2010, 34, 661-666.

5. Kaltschmitt, M.; Weber, M. Markets for solid biofuels within the EU-15. Biomass Bioenerg. 2006, 30, 897-907.

6. Panoutsou, C.; Eleftheriadis, J.; Nikolaou, A. Biomass supply in EU27 from 2010 to 2030. Energ. Policy 2009, 37, 5675-5686.

7. European Commission. Biomass action plan, 2005. Europa Summaries of EU Legislation Web Site. Available online: http://europa.eu/legislation_summaries/energy/renewable_energy/ 127014_en.htm (accessed on 10 May 2012).

8. Celma, A.R.; Rojas, S.; López-Rodríguez, F. Waste-to-energy possibilities for industrial olive and grape by-products in Extremadura. Biomass Bioenergy 2007, 31, 522-534.

9. Messineo, A.; Panno, G. LNG cold energy use in agro-food industry: A case study in Sicily. J. Nat. Gas. Sci. Eng. 2011, 3, 356-363.

10. Messineo, A.; Panno, D. Potential applications using LNG cold energy in Sicily. Int. J. Energy Res. 2008, 32, 1058-1064.

11. Messineo, A.; Marchese, F. Performance evaluation of hybrid RO/MEE systems powered by a WTE plant. Desalination 2008, 229, 82-93.

12. Messineo, A.; Panno, D. Municipal waste management in Sicily: Practices and challenges. Waste Manag. 2008, 28, 1201-1208.

13. Messineo, A.; Culotta, S. Evaluating the performances of small wind turbines: A case study in the south of Italy. Energy Procedia 2012, 16, 137-145.

14. ISTAT Website. Available online: http://agri.istat.it/ (accessed on 2 March 2012).

15. Nastri, A.; Ramieri, N.A.; Abdayem, R.; Piccaglia, R.; Marzadori, C.; Ciavatta, C. Olive pulp and its effluents suitability for soil amendment. J. Hard. Mater. A 2006, 138, 211-217.

16. Caputo, A.C.; Scacchia, F.; Pelagagge, P.M. Disposal of bio-products in olive oil industry: Waste-to-energy solutions. Appl. Therm. Eng. 2002, 23, 197-214.

17. Volpe, R.; Mattei, G.; Di Marco, L. Evaluation of energy content of the wood agri-residuals for auto sustainability of a medium sized farm in Sicily. In Proceedings of the 16th European Biomass Conference and Exhibition, Valencia, Spain, 2-6 June, 2008.

(C) 2012 by the authors; licensee MDPI, Basel, Switzerland. This article is an open access article distributed under the terms and conditions of the Creative Commons Attribution license (http://creativecommons.org/licenses/by/3.0/). 